\title{
O ressurgimento da ZOPACAS e a agenda de segurança no Atlântico Sul
}

Cauê Rodrigues Pimentel

RESUMO: O artigo explora a revitalização da ZOPACAS na agenda de segurança brasileira. Com base no conceito de security governance, argumenta-se que apesar das ambições brasileiras em transformar o Atlântico Sul em espaço privilegiado para sua projeção internacional, a ZOPACAS padece de problemas de institucionalização, agravados pela falta de capacidades materiais e pela concorrência com as grandes potências presentes na região.

Palavras-chave: Atlântico Sul; Segurança regional; Security governance; ZOPACAS.

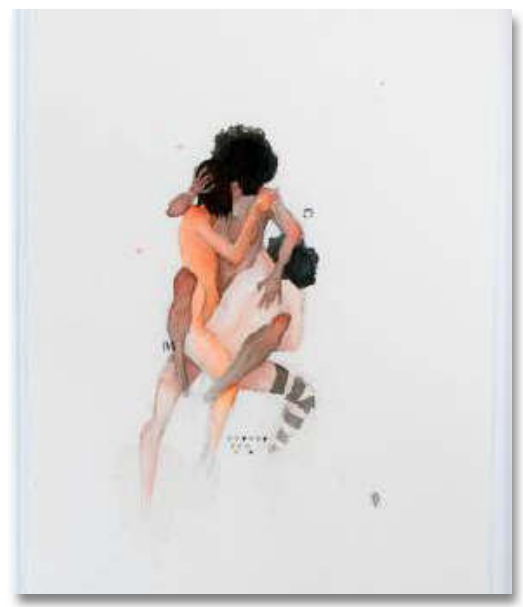

\section{The Resurgence of ZOPACAS and the Security Agenda in the South Atlantic}

\section{Cauê Rodrigues Pimentel}

Doutorando em Ciência Política na Universidade de São Paulo. Investigador Visitante na Universitat de Barcelona. Bacharel em Relações Internacionais pela Universidade Estadual Paulista.

cauerpimentel@hotmail.com
ABSTRACT: The article explored the revitalization of ZOPACAS in the Brazilian security agenda. Based on the concept of security governance, it is argued that despite the Brazilian ambition of transforming the South Atlantic into a privileged space for its international projection, ZOPACAS suffers from problems of institutionalization, aggravated by the lack of material capacity and the competition with the major powers acting in the region.

Keywords: South Atlantic; Regional security; Security governance; ZOPACAS.

$$
\text { ReCEBIDO EM: } 03 \overline{\text { DE AGOSTO DE } 2015}
$$$$
\text { Aprovado em: } 10 \text { DE SETEMBRO DE } 2015
$$

Tensões Mundiais | 113 
Cauê Rodrigues Pimentel

\section{INTRODUÇÃO}

Este breve paper explora a cronologia da Zona de Paz e Cooperação do Atlântico Sul (ZOPACAS) e sua recente revitalização, na agenda de segurança brasileira e regional. Busca reconstruir, sinteticamente, a trajetória desse mecanismo de cooperação em quatro fases, que, entre dinâmicas de ruptura e continuidade, marcam a sua evolução: a fase pré-ZOPACAS, em que é determinante a presença norte-americana e a concorrência, sem sucesso, de diferentes projetos de integração para o Atlântico Sul; a fase originária, marcada pelo conflito britânico-argentino, ainda no contexto dos anos derradeiros da Guerra Fria e da aprovação da Resolução 41/11, que dá origem ao instrumento de cooperação; a fase de regressão, marcada por um interregno de baixas interações transatlânticas e distanciamento das regiões africana e sulamericana; e, por fim, a fase de revitalização da importância estratégica do Atlântico Sul, na política de segurança dos países lindeiros, especialmente na política externa e defesa do Brasil.

A revitalização geoestratégica desse espaço marítimo é motivada por razões endógenas (dinâmicas institucionais e elevação do perfil de atuação regional do Brasil) e exógenas (relevância geoestratégica da região), que serão exploradas ao longo do artigo. A reconstrução da trajetória da ZOPACAS auxilia a requalificar a importância do espaço atlântico, nos quadros da segurança regional, bem como assiste na compreensão do movimento de ascensão do Brasil como líder regional (SCHENONI, 2012; BERTONHA, 2010) e como país que desempenha uma "função insular"1 entre os Complexos Regionais de Segurança sul-americano e africano. A ZOPACAS, devido à sua baixa institucionalização, assimetria de poder e fragmentação de interesses, não se configura como um complexo de segurança regional, mas caminha para o adensamento de uma security governance que serve como plataforma para a defesa de interesses e da soberania dos países desse espaço geográfico.

1 Em seu livro Regions \& Powers, Buzan e Waever (2003) atribuem uma "função insular" (insulators) às unidades do sistema internacional que promovem a interação entre diferentes Complexos Regionais de Segurança, geralmente exercendo significante influência nesses complexos, porém sendo incapazes de unificar os dois, criando, portanto, relações de interpenetração ou overlap entre diferentes dinâmicas regionais de segurança (BARRINHA, 2014). 
O Ressurgimento da ZOPACAS e a agenda de Segurança no AtLÂntico Sul

\section{A FASE PRÉ-ZOPACAS: PROJETOS PARA UM OCEANO}

Desde o início da colonização dos trópicos, o oceano Atlântico exerceu papel fundamental na corrida imperial das potências europeias. O Mare Atlanticum ganhou diferentes contornos cartográficos e políticos, nas mentes dos exploradores portugueses, espanhóis, neerlandeses, britânicos e franceses, cujos interesses se entrecruzavam na longa faixa oceânica atlântica, gerando uma rica confluência que moldaram lentamente a imagem geoestratégica desse oceano. Mais especificamente, a subdivisão do Atlântico Sul começa a surgir no século XVI, pelas mãos de cartógrafos portugueses que vislumbravam o triângulo entre o Equador, o Trópico de Capricórnio e o Círculo Polar como um condomínio exclusivo da coroa lusa. A consagração da figura do South Atlantic seria posteriormente consolidada, no século XIX, no auge da corrida interimperial europeia, dessa vez pela feita dos cartógrafos súditos da majestade britânica, interessada na supremacia extensiva sobre os mares ocidentais (LOIS; GARCIA, 2009).

A acepção estratégica moderna do Atlântico Sul começa a ganhar corpo no século XX, a partir do momento em que a região se torna um capítulo importante nas crônicas da II Guerra Mundial. Para o Brasil, que se viu enredado no conflito europeu devido à sua posição geográfica meridional, com importante inclinação sobre o território africano, o Atlântico Sul se tornou uma barganha estratégica. A saliência do território nordestino - "a plataforma da vitória" - aproximou o Brasil do conflito internacional e deu novo significado à presença do país, na região atlântica (SILVA; LEÃO; ALMEIDA, 2013).

Apesar da importância do Atlântico Sul, durante os anos da guerra contra o Eixo, as décadas seguintes testemunharam um declínio estratégico da região, principalmente em relação à sua contraparte, o norte, que se tornou o foco do engajamento norte -americano. Apesar do baixo interesse estratégico e das rarefeitas relações no eixo Sul-Sul do oceano, verifica-se o surgimento das primeiras iniciativas de cooperação, em matéria de segurança para a região, articuladas dentro do quadro da Organização dos Estados Americanos (OEA), sob a hegemonia dos Estados Unidos da América (EUA). As principais ações para a segurança da região, 
Cauê Rodrigues Pimentel

nesse primeiro momento, partiram da Junta Interamericana de Defesa (JID), fundada em 1942, que preconizava a ameaça comunista como o maior problema da segurança hemisférica. Em função dessa preocupação, surge, em 1959, a UNITAS, um exercício naval realizado todos os anos desde então, envolvendo as Marinhas de todo o hemisfério americano, além da criação da Área Marítima do Atlântico Sul (AMAS), estabelecida, em 1967, pela JID para coordenar e monitorar o tráfego marítimo na zona (AGUILAR, 2013). Não obstante, os EUA diminuem sua presença direta na região, ao desmobilizarem a IV Frota Norte-americana ${ }^{2}$ criada em 1943, para o teatro de operações do Atlântico Sul e que deixaria de existir ainda em 1950.

Para além da hegemonia norte-americana, propostas para uma maior integração em prol da segurança do Atlântico Sul surgiram, a partir das vozes de países sul-americanos e africanos. Ainda na década de 1950, a Argentina realizou consultas aos governos do Brasil e do Uruguai, para a construção de uma defesa articulada do Atlântico Sul. Essa aproximação não obteve grandes sucessos, principalmente devido às desconfianças mútuas entre os setores civis e militares de Brasil e Argentina. Rivalidades regionais no eixo dinâmico do Prata se sobrepunham às questões de segurança do Atlântico Sul (PENNA FILHO, 2003).

A década de 1960 presencia o surgimento de novas propostas para a integração do Atlântico Sul. Nesse momento, a África do Sul passa a apostar na criação da Organização do Tratado do Atlântico Sul (OTAS), nos moldes da OTAN. O governo sul-africano enxergava a construção de tal mecanismo como uma importante válvula de escape, para romper seu isolamento internacional em função do regime do apartheid. A proposta sul-africana, aventada pela primeira vez em 1966, apostava na criação de um mecanismo integrado de segurança que envolvesse Brasil, Argentina, Uruguai, Chile, Portugal, Austrália, Nova Zelândia e a África do Sul (PENNA FILHO, 2003), na proteção do espaço atlântico e pacífico, contra a ameaça soviética, que estaria transformando a zona em um "lago comunista" (HURRELL, 1983). A ideia, apesar da reiterada

2 A IV Frota contava com 4 cruzeiros, 4 destróeirs, 13 fragatas e um navio hospital, totalizando 21 embarcações, mobilizadas no espaço atlântico. 
O Ressurgimento da ZOPACAS e a agenda de Segurança no AtLÂntico Sul

insistência de Pretoria, não avançou. Entre os principais motivos para o fracasso dessa proposta, pode-se destacar a ambivalência que os governos sul-americanos mantinham em relação à África do Sul, uma vez que uma aproximação com a Pretoria se fazia, em detrimento das relações com as outras nações da África Subsaariana. Já sobre a factibilidade da ameaça soviética na região, a bibliografia apresenta divergências: enquanto alguns textos apontam que a percepção da África do Sul - e da imprensa daquele país - era suficiente para mobilizar a opinião pública sobre a plausibilidade de uma invasão soviética (PENNA FILHO, 2013), parte da bibliografia aponta, a posteriori, que a presença soviética no Atlântico era menor do que supunham os militares da região e que ela não era uma ameaça direta à integridade territorial desses Estados (BOOTH, 1987; GIBRAN, 1998).

Não obstante o fracasso inicial da OTAS, a ideia foi ressuscitada em 1977 pelo Uruguai, que aventou a possibilidade de um projeto de integração com a participação dos EUA. Dessa vez, a proposta não avançou devido a uma negativa do governo brasileiro, pautada no "pragmatismo responsável" do governo Geisel, o qual passara a condenar qualquer aproximação com o regime sul-africano. Paralelamente, a administração Geisel ${ }^{3}$ buscava maior independência em relação ao conflito leste-oeste, sobretudo em relação ao discurso de segurança hemisférica dos EUA, movimento que culmina no rompimento de acordo militar com aquele país, em 1977, como reflexo das críticas da administração Carter ao governo brasileiro em matéria de direitos humanos e pelas tentativas dos estadunidenses de frustrarem $\mathrm{O}$ acordo nuclear Brasil-Alemanha. Em relação à OTAS, a recusa brasileira aduzia que a criação de semelhante mecanismo levaria a uma possível corrida armamentista na região, sendo que os países da faixa do Atlântico Sul não teriam como competir com as capacidades das duas superpotências (PEREIRA, 2013). Desse modo, a institucionalização da cooperação em defesa no Atlântico Sul era percebida como indesejável pelas autoridades brasileiras.

3 De 1973 a 1979, período do "Pragmatismo Responsável e Ecumênico", sob o comando do chanceler Azeredo da Silveira. 
Cauê Rodrigues Pimentel

A recusa brasileira ao projeto da OTAS não significava que o país não atribuía importância ao espaço atlântico. Pelo contrário: a década de 1970 é talvez o momento em que o Atlântico Sul passa a ser uma preocupação permanente no pensamento geopolítico das três casas militares. É durante o regime militar brasileiro que a geopolítica encontra seu ápice de desenvolvimento intelectual e institucional, atingindo as mais altas instâncias decisórias do Estado e passando a integrar as estratégias de defesa e de inserção internacional do país. Mais: o pensamento geopolítico embasou o projeto de um Brasil potência, com clara vocação hegemônica no entorno estratégico da América do $\mathrm{Sul}^{4}$ (MIYAMOTO, 1989). O Atlântico Sul aparece como uma vertente fundamental da expansão do poder brasileiro no "modelo travassiano", posteriormente sistematizado por Golbery Couto e Silva e Meira Mattos e, finalmente, institucionalizado nas estruturas militares pela Escola Superior de Guerra (VIEIRA, 2008). Desde então, o Atlântico Sul passou a integrar a agenda externa brasileira, seja na pauta de prioridades do Itamaraty, seja na dos militares, constituindo-se um ativo estratégico no contexto da inserção internacional do Brasil, tendência que se reforça no início do século XXI.

Na geopolítica de Mattos (1975), o Atlântico Sul aparece materializado como a grande fronteira oriental do Brasil. O general apontava a costa africana como uma peça fundamental da defesa do território nacional, faixa onde se iniciariam as preocupações de defesa do país, consagrando, assim, a ideia de defesa distante. Em contrapartida, a grande massa oceânica do Atlântico se tornaria um "espaço de responsabilidades" do Brasil, instando uma maior presença e liderança sobre a região. Essa mentalidade militar que enxerga na posição geográfica brasileira um "destino manifesto" sobre o Atlântico constitui uma peça importante do quebra-cabeça da revitalização desse espaço, como grande objetivo geoestratégico no século XXI, uma vez que parte do discurso geopolítico passa a ser reincorporado às leituras contemporâneas do Atlântico Sul.

4 Como aponta Child (1979), a geopolítica latino-americana das décadas de 1960 e 1970 serviu como substrato indispensável para um projeto nacional que mesclava geografia, estratégia militar, desenvolvimento nacional e expansionismo, com importantes variações nacionais em cada país da região. 
O RESSurgimento da ZOPACAS e a Agenda de SEgurança no Atlântico Sul

Durante a década de 1970, outro evento marca a importância do Atlântico Sul para a política externa brasileira: o pleito da diplomacia nacional, em favor da expansão dos limites ultramarinos do país, objetivo concretizado em 1970 por meio do decreto-lei 1098, que expandiu para 200 milhas o mar territorial brasileiro (CARVALHO, 1999). Segundo Morris (1979), preocupações de natureza doméstica mesclavam-se aos objetivos materiais de caráter econômico que a expansão ensejava. Na opinião desse autor, dois fatores devem ser considerados para explicar tal movimento da diplomacia brasileira. Em primeiro lugar, a expansão das 200 milhas era vista pelo governo como uma medida com impacto positivo na opinião pública de forma a minimizar o desgaste interno resultante da promulgação do Ato Institucional $\mathrm{n}^{\circ}$. Apesar de haver pouca informação do público sobre a relevância da ampliação do domínio marítimo, o governo via a medida como um tema de inspiração nacionalista com apelo popular. O embaixador e ex-ministro das Relações Exteriores, Araújo Castro, comenta a tese de Morris e, sem refutá-la por completo, reforça a dimensão de que os "fatores econômicos, de segurança e político-diplomáticos eram mais do que suficientes para justificar e recomendar a ampliação da soberania do país" (CASTRO, 1989, p. 28). Mesmo dando primazia à raison d'état, como é de se esperar da função diplomática, o ministro concorda que a consciência de que a medida teria boa repercussão interna facilitou a tomada de decisão por parte do Itamaraty. Ademais, o ministro comenta que a Marinha via a expansão das fronteiras como um incentivo para a concessão de uma maior fatia de recursos e investimentos do orçamento federal ao poder marítimo.

Esses episódios denotam, em traços gerais, que o Atlântico Sul fora uma preocupação geopolítica persistente nas formulações de defesa dos diferentes países que dividem a bacia atlântica. Igualmente, esses países vislumbravam a presença soviética, real ou imaginada, como a principal ameaça à segurança da região. Apesar desses pontos de concordância, a percepção mútua negativa entre seus agentes - especialmente nos binômios EUA-Brasil, Argentina-Brasil e Brasil-África do Sul - inviabilizaram qualquer proposta de maior coordenação ou institucionalização 
Cauê Rodrigues Pimentel

duradoura em defesa da região. De todas as formas, durante ese período, o Atlântico Sul voltou a figurar no campo de disputas, materiais e simbólicas, da política externa dos países da bacia.

\section{A FASE ORIGINÁRIA: A CRIAÇÃO DA ZOPACAS}

A fase originária da ZOPACAS pode ser traçada a partir de 1982, quatro anos antes da Resolução 41/11, que criaria esse instrumento. O evento capital que define o início dessa fase é a Guerra das Malvinas, episódio que reorientou as percepções entre os países da região, principalmente no tocante às identidades de segurança que guiavam o pensamento estratégico de Brasil e Argentina. Diferentemente dos prognósticos dos militares da região, já apontados, o conflito em águas atlânticas não envolveu um confronto com bloco soviético, mas se materializou em um embate contra uma potência extrarregional ocidental nuclearizada - o Reino Unido - cujos laços com o continente sul-americano são históricos e marcantes.

Simultaneamente à deterioração das relações do continente sul-americano com o eixo Norte, as relações entre Buenos Aires e Brasília experimentaram significativo incremento com a posse de João Figueiredo e seu engajamento pessoal nas questões com a Argentina, principalmente na solução sobre a utilização dos recursos hídricos, no Prata (SPEKTOR, 2002). Essa significativa melhora nas relações bilaterais propugnou a assinatura de diversos acordos entre os dois países, inclusive de natureza militar, envolvendo projetos de fabricação conjunta de aviões, mísseis e satélites, além da transferência de urânio da Argentina para o Brasil, um setor que, durante décadas, alimentara a desconfiança recíproca. No plano do poder naval, o exercício bilateral Fraterno institucionaliza a cooperação entre as Marinhas dos países. Com o irrompimento do conflito nas Malvinas, a "neutralidade imperfeita" do Brasil, com declarada simpatia pelo pleito argentino, contribuiu para reforçar os laços positivos que abririam caminho para uma fase de integração regional capitaneada pelos dois países (MONIZ BANDEIRA, 2012). Apesar de terem percebido o movimento ofensivo da Argentina nas Malvinas com alguma preocupação, as autoridades 
O Ressurgimento da ZOPACAS e a agenda de segurança no AtLÂntico Sul

brasileiras sempre apoiaram a legitimidade do pleito argentino. Adicionalmente, essas autoridades interpretaram que o apoio do governo Reagan aos britânicos era um indicativo de que os países da América do Sul não poderiam contar com a solidariedade hemisférica em assuntos de segurança internacional: era necessário um maior engajamento dos atores regionais na construção de arquitetura de segurança independente da potência estadunidense (MALLEA; SPEKTOR; WHEELER, 2015, p.17). Nesse sentido, a crise entre Argentina e Grã-Bretanha adquiriu, rapidamente, a coloração de um conflito Norte-Sul que demoliu os "mitos da solidariedade continental e do inimigo comum" (JAGUARIBE, 1986, p. 227). O conflito, motivado, sobretudo, por questões ideológicas e domésticas da Argentina e da Grã-Bretanha, ${ }^{5}$ promoveu um realinhamento das ideias de segurança no Cone Sul. Entrementes, o conflito instilou, no pensamento da Marinha brasileira, a necessidade de dotar o país com uma Armada de alto nível tecnológico, principalmente no que diz respeito à utilização de submarinos convencionais e nucleares (VIDIGAL, 1984, p. 113). Por essas razões, o conflito teve impacto político-estratégico definitivo para a região: determinou diretrizes estratégicas que enfatizavam o Atlântico Sul como espaço de choque de interesses; impôs transformações domésticas aos regimes militares da região; 6 e criou um problema diplomático e estratégico de difícil equação, ${ }^{7}$ nas baixas latitudes do oceano Atlântico (COGGIOLA, 2012; MELLO, 1997; RUSSELL, 1984).

5 Segundo Moneta (1984), um estudo detalhado do processo de decisionmaking durante o conflito, em ambos lados beligerantes, evidencia como fatores ideológicos, concepções de mundo e interesses corporativos influenciaram, sobremaneira, o desenrolar do conflito, muito mais do que imperativos de segurança.

6 Segundo Moniz Bandeira (2012), o episódio das Malvinas alterou a percepção dos norte-americanos sobre a utilidade dos regimes militares na América Latina. Se antes os governos militares eram considerados bastiões de estabilidade e resguardo anticomunista, após o conflito argentino-britânico, os EUA repensariam seu apoio aos regimes militares no continente.

7 De acordo com Saint-Pierre (2014), a percepção argentina no Atlântico Sul se tornou exacerbadamente "malvinocêntrica", fato que limita a capacidade de elaboração estratégica daquele país e dificulta uma cooperação mais ampla sobre a segurança regional no espaço atlântico. 
Cauê Rodrigues Pimentel

A aproximação entre Brasil e Argentina permitiu a modificação das identidades e percepções de ameaças entre esses dois países e que ambos dedicassem maior enfâse a questões geopolíticas em outras frentes estratégicas, sobretudo, o Atlântico Sul. No caso argentino, houve uma acentuada reorientação do regime militar, em direção ao que a geopolítica argentina denominou de "Mar Argentino": o triângulo entre o Rio da Prata, as ilhas Malvinas e o Canal de Beagle. Tendo resolvido as querelas em relação ao Rio da Prata, as outras duas regiões se tornaram os pontos cardeais da política Argentina, sendo que os dois casos resultaram em conflitos diretos com a Inglaterra e o Chile (PENHA, 2011). Do lado brasileiro, o Atlântico Sul ganharia, parecidamente, relevância como vetor de preocupação estratégica e atuação para a construção da política de segurança e da doutrina militar no pós-Guerra Fria.

A aventura argentina no caso das Malvinas promoveu uma transformação importante na percepção dos países da região, em relação ao Atlântico Sul. Apesar de Buenos Aires ter sido o agente agressor, os países da região, sobretudo, Brasil e Argentina, passaram a perceber as "potências extrarregionais" como as maiores ameaças ao espaço atlântico. Não se tratava mais somente da ameaça soviética, mas a tese da geopolítica regional passava agora pelas potências ocidentais do Atlântico Norte: EUA, Inglaterra e França passariam a figurar, no imaginário dos países da região, como agressores em potencial. O fato de a percepção sobre o Atlântico Sul ser radicalmente modificada ainda nos anos finais do conflito bipolar demonstra que algumas transformações importantes, nos subsistemas regionais de segurança, não decorreram somente do colapso das estruturas da Guerra Fria, mas foram condicionadas por eventos de menor dimensão sistêmica, mas com profundo significado regional. ${ }^{8}$

Essa representação da ameaça das potências extrarregionais seria o ponto central da Resolução 41/11 da Assembleia Geral

8 Eventos como o conflito nas Malvinas, o processo de democratização na África e na América do Sul, a piora nas relações hemisféricas da América Latina com os EUA, entre outros eventos que não estão relacionados apenas ao conflito bipolar. 
O Ressurgimento da ZOPACAS e a agenda de segurança no AtLÂntico Sul

das Nações Unidas, patrocinada pelo Brasil e aprovada em 1986 - com voto contrário de Washington -, criando a ZOPACAS. A resolução propugnava os países do Atlântico Sul a uma maior cooperação, no tocante a três áreas - conservação do meio ambiente, desenvolvimento econômico e social e promoção da paz e segurança na região -, além de instar os "países militarmente significativos das outras regiões" a respeitarem a soberania, a independência e a integridade territorial dos países da região.

Apesar de se apresentar como um projeto de pretensões multidimensionais, extrapolando o caráter exclusivo dos problemas e da segurança, fica evidente que a dimensão da defesa assume papel especial, na configuração da ZOPACAS. A questão militar foi também o principal ponto de atrito entre as duas principais instâncias envolvidas, no processo diplomático da criação da zona, a Marinha e o Itamaraty. O embate entre as duas instâncias se centrava nas definições conceituais da zona de paz, sobretudo, na disputa entre desmilitarização e não-militarização do espaço atlântico. Prevaleceria a posição das Forças Armadas, ao defender uma versão flexibilizada da não-militarização e propugnar que o Atlântico Sul deveria se afastar da corrida armamentista das potências bélicas, mas sem que tal proposta impedisse que os países lindeiros desenvolvessem capacidades dissuasórias em seu espaço nacional marítimo9 (PENHA, 2011). Desse modo, a ZOPACAS falava em paz, mas sem excluir o desenvolvimento bélico (MIYAMOTO, 1998). Essa contradição, no entanto, não é uma exclusividade da ZOPACAS, mas um reflexo das dinâmicas de segurança da Guerra Fria e da proliferação de regionalismos de segurança, rotulados como zonas de paz "quentes", pautadas pela ideia de neutralidade ou afastamento da dinâmica da bipolaridade (KACOWICZ, 1998; BUZAN; WAEVER, 2003).

9 Ao mesmo tempo em que defendia uma visão soberanista que pregava a dissuasão das potências estrangeiras, a Marinha manifestou, em diversos documentos, a posição delicada que tal empreendimento poderia causar ao afastar o Brasil de uma cooperação mais estreita com as Marinhas dos países desenvolvidos, fator que poderia prejudicar a obtenção de novos armamentos e novas tecnologias para a Esquadra brasileira (LUIS, 2013). 
Cauê Rodrigues Pimentel

Criada a ZOPACAS, aventou-se uma nova fase de cooperação entre os Estados da região. Pela primeira vez, os países do eixo Sul-Sul conseguiam uma iniciativa de cooperação para o Atlântico Sul, sem a ingerência de potências externas. Tais expectativas por maior integração sul-atlântica logo sofreriam os constrangimentos econômicos e políticos que atingiram os países sul-americanos e africanos, durante a década de 1990.

\section{A FASE DE REGRESSÃO: DESENGAJAMENTO MULTILATERAL E PARCERIAS SELETIVAS NO ESPAÇO SUL-ATLÂNTICO, NA DÉCADA DE 1990}

A primeira reunião da ZOPACAS teve lugar no Rio de Janeiro, reflexo do protagonismo brasileiro, em 1988. Em seguida, uma nova reunião, em 1990, foi realizada em Abuja, Nigéria, porém poucos avanços materiais foram alcançados. Após um intervalo de quatro anos, a III Reunião dos países da zona aconteceu em Brasília, levando à assinatura da Declaração de Desnuclearização do Atlântico Sul, da Declaração do Meio Ambiente Marítimo, e da Declaração da Cooperação Comercial no Atlântico Sul (PENHA, 2011). Em 1996, no IV Encontro da zona, novas promessas de cooperação foram assinadas, porém o que se verifica, na realidade, é uma perda na dinamicidade das relações entre os países costeiros do Atlântico Sul, revelada pelo declínio no comércio da região e fechamento de embaixadas brasileiras no continente africano (SARAIVA, 2012).

A fase de regressão é caracterizada pela perda de relevância da ZOPACAS, pelo desengajamento dos países nos esforços de continuidade de uma cooperação ativa e pela diminuição da relevância do Atlântico Sul, como preocupação geopolítica. Diferentemente das duas fases anteriores, esta fase não possui um evento internacional ou um marco normativo que delimite sua dimensão. Poder-se-ia estabelecer a V Reunião da ZOPACAS, em Buenos Aires, em 1998, como um possível marco, uma vez que aquela foi a última reunião, antes de um interregno de oito anos de abandono da iniciativa atlântica. Porém, mais importante do que um marco temporal, é relevante identificar as causas que levaram 
O Ressurgimento da ZOPACAS e a agenda de segurança no Atlântico Sul

à estagnação da ZOPACAS, como projeto birregional. Múltiplos fatores influenciam o enfraquecimento dessa zona de cooperação: o primeiro fator trata-se da própria perda de relevância estratégica, desempenhada pelo Atlântico Sul, no cenário global do pós-Guerra Fria. Uma menor importância dos temas de segurança, na agenda política desses países, teria levado à perda do contexto original e da ameaça de conflito potencial, presentes na concepção da proposta da ZOPACAS (PENHA, 2011). Essa explicação geopolítica, somada aos prospectos de uma paz liberal, teriam levado a uma menor relevância do espaço atlântico.

Não menos importante é a hegemonia estadunidense no imediato pós-Guerra Fria. A ideia de uma presença unipolar dos EUA é fundamental para entender as transformações, na agenda de segurança hemisférica, na década de 1990, que levaram à substituição de foco, nos problemas de segurança. No lado sul-americano do oceano atlântico, as perspectivas de ameaças tradicionais de segurança são enfraquecidas e parcialmente substituídas por novos temas de segurança, sobretudo, o combate às drogas segundo os interesses de uma agenda fortemente influenciada pelas dinâmicas da superpotência norte-americana (LOVEMAN, 2006). A influência transregional dos Estados Unidos, nos assuntos de segurança da América Latina, foram determinantes durante a década de 1990, seja no sub-complexo andino, seja no espaço do Cone Sul banhado pelo atlântico. ${ }^{10} \mathrm{Na}$ margem africana do Atlântico Sul, a década de 1990 é marcada pela emergência de questões domésticas de segurança, violência étnica e guerras civis, resultantes de um processo de desagregação de instituições estatais frágeis (CAWTHRA et al., 2001; BUZAN; WAEVER, 2003). Desse modo, as duas margens do Atlântico Sul são atingidas por novas dinâmicas de segurança, que tornam a defesa do espaço um assunto não prioritário, nas agendas nacionais de defesa.

10 Como apontam Fawcett e Hurrell (1995), Brasil e Argentina enfrentaram uma posição de constrangimento econômico e militar que limitou dinâmicas autônomas de segurança na região. Esses países assumiram uma posição intermediária - nem de aliança, nem de confrontação em relação aos EUA - em uma tentativa, por vezes oscilante, de conservar sua independência decisória. 
Cauê Rodrigues Pimentel

Parte da bibliografia que abrange as relações interacionais do Brasil com a África se refere à década de 1990 como uma fase marcada por "rupturas e reveses", na cooperação atlântica (PENHA, 2011) e por acentuado declínio nas relações Brasil-África (RIBEIRO, 2007); visões que são sintetizadas pela expressão de um "silêncio atlântico" durante esse período (SARAIVA, 2012). Essa bibliografia enfatiza o desengajamento brasileiro, no continente africano, ao basear seu argumento no relativo declínio das relações entre o Brasil e a África, marcado: pela queda na corrente do comércio bilateral, o qual ficaria limitado a apenas $2 \%$ do comércio internacional do Brasil; pelo realinhamento da política externa de Collor, Itamar e Fernando Henrique Cardoso, com uma agenda internacional voltada prioritariamente para as relações com os países desenvolvidos - consequentemente desvencilhando o Brasil de uma identidade terceiro-mundista dos governos Figueiredo e Sarney -; pela diminuição de uma dependência relativa do Brasil nas importações de petróleo; pela hibernação dos projetos de cooperação na ZOPACAS; e por uma desconstrução gradual do imaginário político e cultural que havia aproximado o Brasil do continente africano, em décadas anteriores (SARAIVA, 1996).

A perda de adensamento nas relações com a África, na década de 1990, é visível quando analisados principalmente os dados referentes às relações econômicas. Menos evidente, no entanto, é esse fenômeno, quando observada a dimensão política nas relações atlânticas. Os anos de 1990 possuem marcos importantes, ao menos embrionários, no avanço das relações com o continente africano: contudo, essas iniciativas não devem ser superlativadas. Mais do que um engajamento sistemático e abrangente no continente africano, concebido como estratégia coerente da inserção internacional brasileira, as iniciativas, durante a década de 1990, são caracterizadas pela seletividade e pela escolha de parceiros pontuais - sobretudo, África do Sul, Angola e Nigéria (RIBEIRO, 2009). A maior iniciativa multilateral do Brasil, na região, foi a criação da Comunidade dos Países de Língua Portuguesa ${ }^{11}$ (CPLP),

11 Angola, Brasil, Cabo Verde, Guiné-Bissau, Moçambique, Portugal, São Tomé e Timor Leste. 
O RESSurgimento da ZOPACAS e a Agenda de SEgurança no Atlântico Sul

em 1996, movimento que consolidava uma aproximação cultural e diplomática com os países africanos, ainda que, do ponto de vista material, fosse um projeto de pouca densidade política e econômica (SARAIVA, 2001; DOPCKE, 2002; MIYAMOTO, 2009).

O distanciamento em relação à África é menos evidente, quando se desloca o foco de atenção do Itamaraty para outras instituições embricadas no relacionamento bilateral com esse continente - nesse sentido, ganha destaque o papel da Marinha. Em 1994, essa instituição deu início a um projeto de cooperação com a Namíbia, através da assinatura do Acordo de Windhoek, cuja prioridade era a formação de oficiais e a criação de um Ministério da Defesa, naquele país. Esse acordo é significativo, pois marca o primeiro movimento autônomo da Marinha na África, em busca de parcerias de cooperação bilateral. A relação da Marinha com a Namíbia se tornou um caso de "relações privilegiadas" para a instituição: desde então, o Acordo de Windhoek foi renovado duas vezes, em 2001 e 2009; paralelamente, durante o período de 1999 a 2014, foram adestrados 1.768 oficiais namíbios; e, em 2004, a Marinha doou uma corveta à Namíbia, além de ter vendido dois patrulheiros para aquele país, em 2009 e 2011 (SEABRA, 2013; LIMA, 2015).

O caso da Namíbia é apenas um dos que demonstram que, apesar de uma queda global nos fluxos de trocas comerciais com a África, durante os anos 1990, os contatos políticos, sobretudo no campo da defesa, aumentaram. Outros acordos bilaterais ilustram essas novas conexões: o acordo no Domínio dos Transportes Marítimos com Angola (1989); o Acordo de Cooperação Militar com Cabo Verde (1994); o Acordo de Cooperação Militar com o Mali (1996); o Acordo de Cooperação Militar com a República Democrática do Congo (2003); o Acordo de Cape Town em Matéria de Defesa, com a África do Sul (2003); e a participação de tropas brasileiras na UNAVEM I, em Angola (1996), e na missão de paz do Congo (2003). Durante os anos 1990, a Marinha também aprofunda seus laços, em relação à participação em exercícios multilaterais de adestramento naval. Para além dos exercícios da UNITAS - orquestrado pela OEA - e da Operação Fraterno - organizada bilateralmente por Argentina e Brasil desde 1982 -, a Marinha cria, 
Cauê Rodrigues Pimentel

em 1993, no bojo da ZOPACAS, a operação ATLASUR, com a participação de Argentina, Brasil e África do Sul, e, posteriormente, Uruguai. Ao final da década, é criado o Exercício Felino, composto pelos países da CPLP. Já nos anos 2000, dois novos exercícios navais são criados: o IBSAMAR, em 2005, transcendendo os limites do Atlântico Sul ao juntar Índia, Brasil e África do Sul; e o exercício Atlantic Tidings, fundado em 2004, com Brasil, Angola, África do Sul, Namíbia e República Democrática do Congo (AGUILAR, 2013). No tocante à cooperação das escolas navais, as instituições ligadas à Marinha - a Escola Naval e o Centro de Instrução Almirante Wandenwolk - treinaram, para além dos quase 1800 oficiais da Namíbia, outros 139 oficiais de Moçambique, Angola, África do Sul, Cabo Verde, Nigéria, São Tomé e Príncipe e Senegal (LIMA, 2015).

Esses dados levam a um questionamento da perspectiva de que os anos 1990 representaram um "silêncio atlântico" da política externa e de defesa. À luz desses elementos, parece ser questionável a afirmação de que o Itamaraty adotou uma política de inspiração kantiana que substituiu a contento a política da doutrina de segurança e a política de defesa, em detrimento do papel das Forças Armadas nessa área (CERVO; BUENO, 2002). Pelo contrário, há indícios de que, apesar de todos os constrangimentos econômicos e políticos da década de 1990, a Marinha ensaiou um maior engajamento com os países costeiros do Atlântico Sul, ainda que com resultados limitados, em função dos constragimentos econômicos da época.

Dessa forma, o Atlântico Sul permaneceu na agenda brasileira de política externa e de defesa, ainda que com menos brilho do que em fases anteriores. Já no início do século XX, o tema ganharia nova dimensão e apareceria como vitrine do engajamento brasileiro, na cooperação Sul-Sul, enquanto potência emergente. 
O Ressurgimento da ZOPACAS e a agenda de Segurança no AtLÂntico Sul

\section{A FASE DA REVITALIZAÇÃO: O RESSURGIMENTO ESTRATÉGICO DO ATLÂNTICO SUL}

A ZOPACAS seria ressuscitada em 2007, quando Angola convocou uma nova reunião para a ativação da zona e assumiu a presidência rotativa do mecanismo, substituindo a Argentina, que havia permanecido oito anos inativa, no assento de chefe da zona. Chama a atenção a iniciativa ter partido de um país que, até então, tinha pouco protagonismo nos assuntos de segurança da região e que era visto, durante os anos da Guerra Fria, como um dos principais focos de instabilidade no Atlântico Sul. A proposta angolana surge meses depois que Luanda ingressa na Organização dos Países Exportadores de Petróleo (OPEP) e se torna um importante ator na exploração petrolífera offshore, localizada no Golfo da Guiné, uma região que tem se destacado como um hub na produção de petróleo, no início do século, concentrando 15\% da produção global desse recurso (BENY, 2007).

Com a reunião patrocinada por Angola e a aprovação do Plano de Ação de Luanda, a ZOPACAS reaparece na agenda regional. Telegramas diplomáticos ${ }^{12}$ sugerem, no entanto, hesitação por parte dos negociadores brasileiros, em relação à proposta angolana. Segundo esses documentos, o Brasil viu-se compelido a aceitar uma reunião para a retomada da ZOPACAS. Apesar da retórica reverencial ${ }^{13}$ às possibilidades de cooperação no Atlântico Sul, a diplomacia brasileira atuou de modo cauteloso, de forma que o organismo permanecesse com baixo grau de institucionalização. ${ }^{14}$ A hipótese para explicar esse comportamento da diplomacia brasileira aponta que o Itamaraty estaria preocupado em gerar grandes expectativas nos países africanos, caso a ZOPACAS ganhasse maior densidade institucional. Uma vez que o Brasil não estava disposto a ser o playmaster da segurança, na região Atlântica

12 Parte importante dos telegramas sobre a negociação com as ZOPACAS, sobretudo os documentos com as diretrizes negociadoras estabelecidas pelo MRE e pela delegação brasileira nas Nações Unidas, permanece inacessível em função do grau de sigilo.

13 Telegrama $n^{\circ}$ 681, 04/07/2007. De Embaixada Brasileira em Luanda para Ministério das Relações Exteriores. Ano 2007, caixa 29.

14 Telegrama $n^{\circ}$ 697, 06/07/2007. De Embaixada Brasileira em Luanda para Ministério das Relações Exteriores. Ano 2007, caixa 29. 
Cauê Rodrigues Pimentel

- tendo, inclusive, rejeitado pedidos para que a Marinha do Brasil patrulhasse a costa ocidental da África. ${ }^{15}$ Esses documentos revelam uma dissonância entre o discurso integracionista brasileiro e a commitement capacity do país, ou seja, a vontade de comprometer-se com uma estratégia de longo prazo, em um engajamento multilateral de grande escopo (NOLTE, 2006).

Apesar da relutância da diplomacia em relação à proposta angolana, a temática da defesa atlântica volta ao centro do debate também por meio da atuação da Marinha, que antes mesmo da renovação da ZOPACAS, em 2006, já vinha propagadeando a importância estratégica do Atlântico Sul, por meio de publicações institucionais, documentos estratégicos e manifestações públicas de oficiais. O termo Amazônia Azul, aventado, pela primeira vez, em 2004, pelo almirante Roberto de Guimarães Carvalho, ressignificava a dimensão do Atlântico Sul na estratégia de defesa do Brasil, criando uma "segunda missão amazônica", para as forças armadas brasileiras. O termo transporta o peso que a Amazônia exerce no ideário nacional e militar, ${ }^{16}$ símbolo maior do mito da grandeza, e o transfere para a questão das fronteiras marítimas. Por estas razões, o debate da Amazônia Azul não é somente um produto de dinâmicas externas, mas é um reflexo da agenda institucional da Marinha brasileira, na busca pela consecução de um projeto de modernização das forças navais e um processo de sedimentação de uma "cultura nacional de segurança" ${ }_{17}^{17}$ projetada na proteção dos recursos naturais do Brasil (MARTINS FILHO; ZIRKER, 2000). ${ }^{18}$

15 Telegrama ${ }^{\circ}$ 256, 24/05/2007. De Secretaria de Estado de Relações Exteriores para Embaixada Brasileira em Luanda. Ano 2007, caixa 29. Mensagem no 282. De Ministério das Relações Exteriores para Ministério da Defesa. Ano 2007.

16 Em entrevista, o ex-presidente Fernando Henrique Cardoso afirmou: "A questão da Amazônia é importante, porque ela dá sentido à missão militar. Ela é necessária e simbólica ao mesmo tempo" (OLIVEIRA, 2005, p.445)

17 Ver Katzenstein (1996) e a definição de que a segurança nacional não é apenas um reflexo de elementos materiais exógenos, mas depende fundamentalmente da combinação desses eventos com fatores institucionais e culturais, que definem as políticas de segurança.

18 Como destaca Oliveira (2005), após a redemocratização e com o desmonte da arquitetura de segurança da Guerra Fria, a missão das Forças Armadas Brasileiras (FAB) deixou de se pautar pela existência de um inimigo expresso e passou a identificar sua missão, com uma gama de interesses a serem 
O Ressurgimento da ZOPACAS e a agenda de segurança no AtLÂntico Sul

Esse debate ganha fôlego com a descoberta das reservas da plataforma do Pré-sal, em 2006, com reservas estimadas entre 5 e 8 bilhões de barris, resignificando a importância das fronteiras marítimas, no projeto de inserção internacional do país (SCHUTTE, 2012). A abundância de recursos naturais, em especial do petróleo, com considerável influência no imaginário nacional, aumenta a percepção de possíveis ameaças no Atlântico Sul. A presença desses recursos passa a ser fonte de riquezas, mas também de ameaças percebidas, a partir de uma leitura hobbesiana da anarquia.

Para além da questão energética, há, simultaneamente, um crescimento de narrativas estratégicas sobre o Atlântico Sul, o que aguça as percepções de ameaça e de amizade-inimizade entre os países da região. É notável, por exemplo, narrativas partindo dos EUA e de Portugal ${ }^{19}$, este no seio da OTAN, visando a atribuir novas dimensões estratégicas ao Atlântico Sul. Uma das explicações possíveis para esse fenômeno é a própria consequência do final da Guerra Fria, com a criação de supostos "vazios de poder" que permanecem relativamente adormecidos, mas que, no início do século XXI, passam por uma disputa simbólica entre diversos atores que tentam aumentar seu raio de influência ou, como aponta Guzzini (2013), passam por um revival de narrativas geopolíticas que atribuem funções renovadas a instituições de política externa e de defesa. No caso norte-americano, por exemplo, é notável a reemergência de um discurso sobre uma bacia atlântica, a qual, na cartografia norte-americana, não distingue as porções norte e sul do Alântico, mas inclui as duas partes dentro de um mesmo contínuo estratégico que reposiciona Washington como um ator decisivo, no eixo do Atlântico Sul, recuperando seu protagonismo

\footnotetext{
defendidos. Nesse contexto, os recursos naturais - e a exaltação nacionalista e romântica da exuberância natural do país - exercem um papel fundamental para fixar a missão das FAB. Outro reflexo dessa construção particular dos problemas de segurança é que os objetivos das FAB se confundem ou se apropriam de missões que fazer referência não a objetivos puramente militares, mas com noções subjetivas de desenvolvimento, soberania, autonomia e mesmo discursos sobre a ordem nacional.

19 Entre outras iniciativas, como a inciativa pessoal do ex-primeiro ministro espanhol José María Aznar na tentativa de impulsionar um projeto intitulado "New Atlantic Community" marcado por questões de energia, segurança e livremercado (AZNAR, 2014).
} 
Cauê Rodrigues Pimentel

de períodos anteriores e propugnando uma nova dimensão para o "Hemisférico Atlântico" (LESSER, 2010; HAMILTON, 2014). Paralelamente, a reativação da IV Frota Norte-americana, em 2008, inativa desde 1950, gerou repercussões negativas nos círculos decisórios e acadêmicos sul-americanos, os quais rapidamente identificaram tal medida com desconfiança (SAINT-PIERRE, 2008). É notável que essa suspeição surja no momento em que ao menos as relações entre Brasil e EUA alcançam um momento de maturidade, estabilidade e "afinidades ideológicas", nas palavras do então chanceler Antônio Patriota (2009). Essa tensão demonstra que a segurança do Atlântico Sul possui elementos e dinâmicas próprias, que contrastam com outros setores das relações diplomáticas. Do outro lado do Atlântico, os norte-americanos criaram, em 2006, o Comando dos Estados Unidos para a África, também conhecido como AFRICOM, que operaria como plataforma para a cooperação militar entre estadunidenses e países africanos. Nesse contexto, intensificaram-se os exercícios navais em conjunto com as marinhas dos países do Golfo da Guiné, na Costa Ocidental da África, e com países da OTAN, em águas sul-atlânticas. ${ }^{20}$

Pela vertente europeia, as novas narrativas do Atlântico Sul partem, sobretudo, de Lisboa, país com histórica relação com os países das duas margens do oceano e com importância fundacional na ideia de um espaço sul-atlântico particular. Assim, o Atlântico Sul sempre esteve no compasso geopolítico de Portugal, um país cuja extensão territorial marítima é dez vezes superior à sua massa continental. O fato novo é a tentativa portuguesa de inserir o Atlântico Sul como um eixo estratégico da OTAN, organização que notadamente tem expandido seu raio de ação para fora de sua zona de competência originária. Ademais, exercícios euro -atlânticos na região da costa africana têm aumentado a presença

20 Merecem destaque as diferentes recepções das iniciativas norte-americanas, nos dois lados do Atlântico Sul. Enquanto a margem sulamericana recebeu tais fatos com desconfiança, os países africanos parecem ter assimilado com menos antipatia a tais iniciativas. Aparentemente, esse interesse múltiplo de diferentes atores na região africana (Brasil, EUA e mesmo China e Índia) cria uma situação de barganha ideal para os governos locais interessados em conseguir dividendos políticos e financiamento externo. 
O Ressurgimento da ZOPACAS e a agenda de Segurança no AtLÂntico Sul

dos países europeus na região (SEABRA, 2013; BIERMANN, 2007; SANTOS, 2011). É notável, portanto, como o espaço geográfico do Atlântico volta a ser palco de uma disputa simbólica entre atores interessados em desempenhar um papel de liderança na região.

Esses fatores combinados levam a um novo equacionamento da política de inserção brasileira, em relação a um espaço marítimo atlântico na Estratégia de Defesa Nacional (EDN) (BRASIL, 2008), materializando-o como uma das "preocupações mais agudas de defesa" e considerando como hipótese de emprego das Forças Armadas a "ameaça de guerra no Atlântico Sul". Para além da EDN, a Marinha brasileira tem mantido importante cooperação bilateral com Angola, São Tomé e Príncipe, África do Sul, Nigéria, Senegal e Moçambique. Com exceção deste último país, todos são parte da ZOPACAS (PENNA FILHO, 2013). Esse dado traz duas perspectivas importantes: em primeiro lugar, ressalta $O$ papel proativo de uma "diplomacia naval", em constante evolução; em segundo lugar, demonstra que o planejamento estratégico da Marinha não se limita à cooperação com a ZOPACAS e que há importantes intersecções (overlap) entre este arranjo de cooperação e a CPLP, no tocante a assuntos relativos à segurança atlântica. ${ }^{21}$ Reforça-se a ideia, portanto, de que a estratégia brasileira no Atlântico Sul não se guia somente pela perspectiva da dissuasão de potências estrangeiras, mas também se materializa em uma estratégia da presença brasileira (OLIVEIRA, 2005), ainda que essa presença seja, comparativamente, menor quando comparada com outras potências e países emergentes.

Após o Plano de Ação de Luanda, as reuniões interministeriais da ZOPACAS foram retomadas anualmente e um segundo encontro de alto nível teve lugar em Montevidéu, em 2013. Nessa reunião, foi assinada a Declaração de Montevidéu, documento extenso que trata de temas variados, como: governança global (incluindo a pauta de Reforma do Conselho de Segurança), desarmamento

21 Servem como exemplos, nesse aspecto, algumas iniciativas da CPLP tais como o Protocolo de Cooperação no Domínio da Defesa; o Programa Integrado de Intercâmbio no Domínio da Formação Militar; as Conferências das Marinhas da CPLP, entre outras (SILVA, 2015). 
Cauê Rodrigues Pimentel

nuclear, paz e segurança, defesa, desenvolvimento e aspectos econômicos, mudança do clima, gestão dos recursos marítimos e crimes transnacionais (com destaque para a pirataria na costa ocidental africana). A promessa de reuniões bianuais de altonível também foi retomada, com a programação de um encontro em Cabo Verde, em 2015. Ainda que as iniciativas tomadas em Luanda e Montevidéu sejam incipientes, as duas reativaram uma agenda própria para o Atlântico Sul, que, sobrepostas, adensam as redes de cooperação na região, contribuindo para a articulação de uma security governance.

A ZOPACAS continua a enfrentar dois fatores que emperram uma maior cooperação entre os atores da região: a pluralidade de interesses e a distribuição assimétrica de capacidades entre os países atlânticos. Enquanto o primeiro fator, a pluralidade de interesses, possui importantes variações cognitivas que, apesar das diferenças significativas, permitiram a aproximação dos países da região nas últimas décadas, o mesmo não pode ser afirmado em relação à distribuição das capacidades, principalmente militares. Apesar de reunir 24 países, é notável que apenas Brasil, Argentina e África do Sul (e, em menor grau, Nigéria e Angola) possuem capacidades para exercer algum poder dissuasório crível na região. Mesmo estes países, no entanto, não dispõem da envergadura necessária para exercer responsabilidades ostensivas sobre o espaço Atlântico.22

Mais do que uma organização com objetivos claros e definidos, sobretudo nos quesitos de segurança e defesa, a ZOPACAS surgiu como uma declaração de intenções com amplo caráter multidimensional; persiste, nesse sentido, certa dificuldade em qualificar a ZOPACAS como instrumento regional de segurança. As categorias de complexo regional de segurança, comunidade

22 A assimetria das capacidades fica evidente quando comparados os orçamentos militares dos países que compõem a ZOPACAS. O orçamento de defesa brasileiro supera em mais de $50 \%$ a soma de todos os outros membros da zona. Em 2013, o orçamento de defesa brasileiro foi de US\$31,5 bilhões. O orçamento dos outros 23 países da ZOPACAS foi de aproximadamente U\$ 21 bilhões, os quais por sua vez são similarmente mal distribuídos, uma vez que Angola (US\$ 6,1 bi) Argentina (US\$ 4,5 bi), África do Sul (US\$ 4,1 bi) e Nigéria (US $\$ 2,1$ bi) correspondem a cerca de um $3 / 4$ do restante total (SIPRI, 2014). 
O RESSurgimento da ZOPACAS e a Agenda de SEgurança no Atlântico Sul

de segurança e regimes de segurança não captam a configuração de interesses e dinâmicas que perpassam a região atlântica e, de modo mais abrangente, algumas características da segurança internacional, no início do século XXI. Alternativamente, a pauta multitemática e a baixa institucionalização da ZOPACAS apontam para a possível conformação de uma security governance no Atlântico Sul, sem que haja uma opção por um mecanismo tradicional de defesa e segurança na região.

De modo geral, a security governance pode ser definida como um conjunto de dinâmicas de segurança, sobrepostas a um determinado tema político ou espaço geográfico, sobre o qual perpassam diferentes filiações institucionais, sem uma clara hierarquia definida. A security governance é marcada por diferentes instituições, práticas e discursos de segurança que não são mutuamente exclusivos. O resultado é um ambiente regional marcado por um intenso overlapping (WEIFFEN; WEHNER; NOLTE, 2013) e, portanto, menos anárquico, mas que não exclui a concorrência interestatal, por mais poder e mais segurança (ADLER; GREVE, 2009).

Apesar da baixa institucionalização, os atores que apostam nesse mecanismo acreditam que esse formato cooperativo contribui para incrementar capacidades operativas (ORSINI; MORIN; YOUNG, 2013), individuais ou coletivas, além de facilitar o consenso normativo sobre agendas de segurança regional. Trata-se de um conceito que busca traduzir a intensa fragmentação dos temas de segurança na agenda internacional e o aumento de instâncias multilaterais de defesa em um estágio de polaridades em definição. Muitas vezes, a security governance emerge quando atores decidem cooperar para resolver um problema específico, como o desenvolvimento de algum tipo de armamento, o treinamento militar ou a troca de informações de inteligência, iniciativas que, eventualmente, levam ao adensamento da cooperação regional entre atores estatais e entre atores não-estatais (KRAHMANN, 2003).

A security governance, ainda que frouxa no nível institucional, provê aos Estados envolvidos um maior grau de legitimidade, nos seus pleitos individuais (principalmente em termos de reafirmação da soberania nacional - um tipo de sovereign-boosting regionalism), 
Cauê Rodrigues Pimentel

criando um modus vivendi - normas e regras - que, ainda que pouco estruturadas, contribuem para organizar as preferências dos atores regionais (KACOWICZ; PRESS-BARNATHAM, 2015), bem como auxiliam na formação de uma identidade estratégica entre atores regionais. Mais do que prover uma arquitetura bem estabelecida de segurança entre os Estados costeiros, a ZOPACAS visa a estabelecer um espaço de coordenação, gestão de riscos comuns e regulação de conflitos com menor grau de interferência de potências extrarregionais (ainda que o overlaping ou a penetração de outras dinâmicas de segurança sejam inevitáveis devido a assimetrias de poder militar e econômico das regiões sulamericana e africana, em relação a outras porções do sistema internacional). A presença de uma identidade (imaginada) comum a esses atores e a existência de um espaço geográfico referencial único facilitam a formação dessa security governance (ABDENUR; MARCONDES, 2014). Ainda que seja difícil mensurar a efetividade de tais mecanismos, especialmente tendo em vista a trajetória tortuosa da ZOPACAS, o fato de tal organismo servir como plataforma de promoção de interesses individuais e como balizador de preferências, nos relacionamentos regionais, já indica sua relevância para entender a complexa teia de dinãmicas de segurança que perpassam a região atlântica.

\section{NOTAS FINAIS}

Esse paper abordou, brevemente, a trajetória sobre a criação de mecanismos multilaterais de cooperação em matéria de defesa e segurança, no espaço do Atlântico Sul. Diversos fatores influenciaram essa trajetória: o baixo nível de adensamento institucional, o baixo registro de guerras interestatais e a presença de assimetrias de poder marcantes. Após décadas de tentativas frustradas para a criação de uma arquitetura verdadeiramente multilateral de segurança, uma nova fase de adensamento de relacionamentos bilaterais e multilaterais começa a surgir, a partir de meados da década de 1980, momento no qual os problemas de segurança do Atlântico Sul deixam de ser percebidos pela ótica do conflito Leste-Oeste e assumem um caráter de cooperação

136 | Tensões Mundiais, Fortaleza, v. 12, N. 22, P. 113-143, 2016 
O Ressurgimento da ZOPACAS e a agenda de Segurança no AtLÂntico Sul

Sul-Sul, com acento de rivalidade Norte-Sul. Dificuldades domésticas e regionais impedem uma maior institucionalização do projeto da ZOPACAS, mecanismo que hibernou desde sua criação, em 1986, até sua reativação, em 2007, período em que se nota um renascimento geoestratégico do Sul do oceano Atlântico, para os países costeiros. Desde então, novas iniciativas - nacionais, bilaterais e multilaterais - reavivem o debate sobre uma arquitetura de segurança regional, no Atlântico Sul. Devido à alta fragmentação da cooperação regional e ao aspecto multivariado dos temas abordados nos processos de integração, conclui-se que o Atlântico Sul aproxima-se da definição de security governance, conceito que exprime uma configuração de segurança regional que, apesar de sua baixa institucionalização e do alto grau de overlapping, contribui para um adensamento das relações sul-atlânticas e permitem o surgimento, ainda que incipiente, de uma identidade estratégica regional. Por meio da utilização desse conceito, tenta-se capturar as multiperspectivas que perpassam o espaço atlântico e que merecem maior investigação, por parte da bibliografia em segurança regional.

\section{REFERÊNCIAS}

ABDNEUR, A.; MARCONDES, D. O Brasil e a cooperação em defesa: a construção de uma identidade regional no Atlântico-Sul. Revista Brasileira de Política Internacional, Brasília, v. 57, n. 1, p. 05-21, 2014.

ADLER, E., GREVE, P. When security community meets balance of power: overlapping regional mechanisms of security governance. Review of International Studies, Cambrigde, v. 35, n. 1, p.5984, 2009.

AGUILAR, S. South Atlantic: Brazil-Africa Relations in the field of security and defense. Austral: Brazilian Journal of Strategy \& International Relations, Porto Alegre, v. 02, n. 04, p.47-68, 2013.

AZNAR, J. Ma. The Case for a New Atlantic Community. Wall Street Journal, 18 mar. 2014. Disponível em: <http://goo.gl/ qBiXH4>. Acesso em: 30 abr. 2015. 
Cauê Rodrigues Pimentel

BARRINHA, A. The ambitious Insulator: Revisiting Turkey's position in Regional Security Complex Theory. Mediterrean Politics, Londres, v. 19, n. 02, p. 165-182, 2014.

BENY, E. A nova geopolítica do petróleo: do Golfo Pérsico ao Golfo da Guiné. Lisboa: Nova Imbondeiro, 2007.

BERTONHA, J. Brazil: an emerging military power? The Problem of the use of force in Brazilian international relations in the 21st century. Revista Brasileira de Política Internacional, Brasília, n. 53, n. 02, p.107-124, 2010.

BIERMANN, R. Towards a Theory of inter-organizational networking: the Euro-Atlantic security institutions interacting. The Review of International Organizations, Berlim, v. 03, n. 02, p.151-177, 2007.

BOOTH, K. Law, Force and Diplomacy at Sea. New York: Routledge, 1987.

BUZAN, B.; WAEVER, O. Regions and Powers: The Structure of International Security. New York: Cambridge Press, 2003.

BRASIL. Ministério da Defesa. Estratégia de Defesa Nacional, Brasília, 2008. Disponível em: <http://goo.gl/hLdGAZ>. Acesso em: 27 abr. 2015

CARVALHO, G. O mar territorial brasileiro de 200 milhas: estratégia e soberania, 1970-1982. Revista Brasileira de Política Internacional, Brasília, v. 42, n. 01, p.110-126, 1999.

CASTRO, A. O Brasil e o Novo Direito do mar: Mar Territorial e Zona Econômica Exclusiva. Brasília: Fundação Alexandre de Gusmão, 1989.

CAWTHRA, G.; PISANI, A. du; OMARI, A. (orgs). Security and Democracy in Southern Africa. Johannesburg: Wits University Press, 2001.

CERVO, A.; BUEnO, C. História da Política Exterior do Brasil. Brasília: EdUnB, 2002.

CHILD, J. Geopolitical Thinking in Latin America. Latin American Research Review, Pittsburgh, v. 14, n. 02, p.89-111, 1979. 
O Ressurgimento da ZOPACAS e a agenda de Segurança no AtLÂntico Sul

COGGIOLA, O. A Outra Guerra do Fim do Mundo: As Malvinas e "Redemocratização" da América do Sul. Aurora, Marília, v. 05, n. 02, p.169-246, 2012.

DOPCKE, W. Tanto inútl quanto desnecessária?. Meridiano 47, Brasília, n. 26, p.22-24, 2002.

FAWCETT, L.; HURRELL, A. Regionalism in World Politics: Regional Organization and International Order. Oxford: Oxford University Press, 1995.

GIBRAN, D. The Falklands War: Britain versus the past in the South Atlantic. North Carolina: McFarland, 1998.

GUZZINI, S. (org.). The Return of Geopolitics in Europe?: Social Mechanisms and Foreign Policy Identity Crisis. New York: Cambridge University Press, 2013.

HAMILTON, D. Generating Growth, Human Development and Security in the Atlantic Hemisphere: a declaration and Call to Action. Center for Transatlantic Relations, Washington DC, 2014. Disponível em: <http://goo.gl/rejMka>. Acesso em: 30 abr. 2015.

HURRELL, A. The Politics of South Atlantic Security: A Survey of Proposals for a South Atlantic Treaty Organization. International Affairs, Londres, v. 59, n. 02, p. 179-193, 1983.

JAGUARIBE, H. Novo Cenário Internacional: Conjunto de Estudos. Rio de Janeiro: Guanabara, 1986.

KACOWICZ, A. Zones of Peace in the Third World: South America and West Africa in Comparative Perspective. New York: State University of New York, 1998.

KACOWICZ, A.; PRESS-BARNATHAM, G. Regional Security Governance. International Studies Association, New Orleans, n. $56, \mathrm{~s} / \mathrm{p} ., 2015$.

KATZENSTEIN, P. (org.). The Culture of National Security: Norms and Identity in World Politics. New York: Columbia University Press, 1996.

KRAHMANN, E. Conceptualizing Security Governance. Cooperation and Conflict, Londres, v. 38, n. 01, p. 05-26, 2003. 
Cauê Rodrigues Pimentel

LESSER, I. Southern Atlanticism: Geopolitics and Strategy for the other half of the Atlantic Rim. Washington: The German Marshall fund of the United States, 2010.

LIMA, R. C. A Articulação entre Política Externa e Política de Defesa no Brasil: uma Grande Estratégia inconclusa. 2015. $257 f$. Dissertação (Mestrado em Relações Internacionais) - Programa San Tiago Dantas de Pós- Graduação em Relações Internacionais, UNESP; UNICAMP; PUC-SP, São Paulo, 2015.

LOIS, C.; GARCIA, J. C. Do oceano dos clássicos aos mares dos impérios: transformações cartográficas do Atlântico Sul. Anais do Museu Paulista, São Paulo, v.17, n. 02, p. 15-37, 2009.

LUIS, C. Ao mar, navegar é preciso: o pensamento estratégico da Marinha vis-a-vis à política externa brasileira. 2013. $144 \mathrm{f}$. Dissertação (Mestrado em Relações Internacionais) - Programa San Tiago Dantas de Pós-Graduação em Relações Internacionais, UNESP; UNICAMP; PUC-SP, São Paulo, 2013.

LOVEMAN, B. Addicted to Failure: US security policy in Latin America and the Andean Region. Lanham: Rowman \& Littlefield Publishers, 2006

MALLEA, R.; SPEKTOR, M.; WHEELER, N. (eds). The origins of Nuclear Cooperation: A critical oral history between Brazil and Argentina. Rio de Janeiro: FGV, 2015.

MARTINS FILHO, J.; ZIRKER, D. Nationalism, National Security and Amazônia: Military Perceptions and Attitudes in Contemporary Brazil. Armed Forces \& Society, Londres, v. 27, n. 01, p.105$129,2000$.

MATTOS, M. Brasil, Geopolítica e Destino. Rio de Janeiro: Biblioteca do Exército, 1975.

MELLO, L. I. A. Argentina e Brasil: A balança de poder no Cone Sul. São Paulo: Annablume, 1997.

MIYAMOTO, S. Geopolítica e Potência: o sonho brasileiro. Revista de Cultura Vozes, Rio de Janeiro, v. 83, p.278-290, 1989.

Atlântico Sul: zona de paz e de cooperação?. Lua Nova, São Paulo, v. 03, n. 03, p.21-23, 1998.

140 | Tensões Mundiais, Fortaleza, v. 12, N. 22, P. 113-143, 2016 
O Ressurgimento da ZOPACAS e a agenda de Segurança no AtLÂntico Sul

O Brasil e a Comunidade de Países de Língua Portuguesa (CPLP). Revista Brasileira de Política Internacional, Brasília, $\mathrm{v}$. 52, n. 02, p. 22-42, 2009.

MONETA, C. The Malvinas Conflict: Analyzing the Argentine Military Regime's Decision-Making Process. In: MUÑOZ, H.; TULCHIN, J. Latin American Nations in World Politics. Colorado: Westview Press, 1984. p. 119-129.

MONIZ BANDEIRA, L. A. Guerra das Malvinas: Geopolítica e Petroleo. Revista Espaço Acadêmico, Maringá, n. 132, p. 157165, 2012.

MORRIS, M. International Politics and the Sea: the Case of Brazil. Boulder: Westview Press, 1979.

NOLTE, D. Potenciais Regionales en la Política Internacional: conceptos y enfoques de análisis. Giga Working Papers, Hamburgo, n. 30, s/p., 2006.

OLIVEIRA, E. R. Democracia e Defesa Nacional: A Craiação do Ministério da Defesa na Presidência de FHC. Barueri: Manole, 2005.

ORSINI, A; MORIN, J.; YOUNG, O. Regime Complexes: A buzz, a boom or a boost for Global Governance. Global Governance, Boulder, v.19, n.1, p.27-39, 2013.

PATRIOTA, A. O Brasil e a Política Externa dos EUA no Governo Obama. Política Externa, São Paulo, v. 18, n. 01, s/p., 2009. Disponível em: < goo.gl/Ggqb6Y>. Acesso em: 11 dez. 2016.

PENHA, E. A. Relações Brasil-África e geopolítica do Atlântico Sul. Salvador: EDUFBA, 2011.

PENNA FILHO, P. Reflexões sobre o Brasil e os desafios do Atlântico Sul no início do Século XXI. Brasília: Ministério da Defesa, 2013. Disponível em: <http://goo.gl/hq4GQB>. Acesso em: 19 jul. 2015.

Regionalismo, Segurança e Cooperação: o Atlântico-Sul como Espaço de Possibilidades entre o Cone-Sul e África Austral. In: ENCONTRO NACIONAL DA ANPOCS, 27, 2003, Caxambú. Anais... Caxambú: s/ed, 2003. p. 01-22. Disponível em: <http://www. anpocs.org/portal/index.php?option $=$ com_docman\&task $=$ doc download\&gid=4291\&Itemid=216>. Acesso em: 24 jun. 2005. 
Cauê Rodrigues Pimentel

PEREIRA, A. The South Atlantic, Southern Africa and South America: Cooperation and Development. Austral: Brazilian Journal of Strategy \& International Relations, Porto Alegre, v. 02, n. 04, p. 31-45, 2013.

RIBEIRO, C. As Relações Brasil-África nos governos Collor e Itamar. Revista Brasileira de Ciência Política, Brasília, n. 01, p. 289-329, 2009.

Relações Político-comerciais Brasil-África (19862006). 2007. 243f. Tese (Doutorado em Ciência Política) Programa de Pós-Graduação em Ciência Política, Faculdade de Filosofia, Letras e Ciências Humanas, Universidade de São Paulo, São Paulo, 2007.

RUSSELL, R. (org.). América Latina y la Guerra del Atlántico Sur. Buenos Aires: Belgrano, 1984.

SAINT-PIERRE, H. Una reflexión estratégica sobre el Atlántico Sur: más allá de las Malvinas. In: SEMINARIO INTERNACIONAL, 2. 2013, Río Grande - Tierra del Fuego. Palestra gravada. Vídeo (aprox. 25 min). Disponível em: <https://goo.gl/Fddsf2>. Acesso em: 10 set. 2015.

La Activación de la IV Flota de los Estados Unidos y las hipótesis evitables. Lima: IDEPE, 2008. Disponível em: <http://goo.gl/CBpDZJ>. Acesso em: 29 abr. 2015.

SANTOS, J. A. Uma Visão Portuguesa da Segurança do Atlântico Sul. Nação e Defesa, Lisboa, n. 128, p. 19-28, 2011.

SARAIVA, J. F. S. África parceira do Brasil atlântico: relações internacionais do Brasil e da África no início do século XXI. Belo Horizonte: Fino Traço, 2012.

(org). Comunidade dos Países de Língua Portuguesa (CPLP): solidariedade e ação política. Brasília: Instituto Brasileiro de Relações Internacionais, 2001.

O lugar da África. Brasília: EdUnB, 1996.

SEABRA, P. Dinámicas de seguridad en el Atlántico Sur: Brasil y Estados Unidos en África. Revista CIDOB d'afers Internacionals, Barcelona, n.102-103, p. 199-218, 2013.

SCHENONI, L. Ascenso y hegemonía: pensando a las potencias

142 | Tensões Mundiais, Fortaleza, v. 12, N. 22, P. 113-143, 2016 
O Ressurgimento da ZOPACAS e a agenda de Segurança no AtLÂntico Sul

emergentes en América del Sur. Revista Brasileira de Política Internacional, Brasília, v. 55, n. 01, p.31-48, 2012.

SCHUTTE, G. Panorama do Pré-Sal: Desafios e Oportunidades. Brasília: IPEA, 2012.

SILVA, D. D. da. O Atlântico de Língua Portuguesa em Perspectiva Comparada de Segurança e Defesa: dos documentos políticos ás elaborações estratégicas (1996 a 2013). 2015. 340f. Tese (Doutorado em História Comparada) - Programa de Pós-Graduação em História Comparada, Instituto de História, Universidade Federal do Rio de Janeiro, Rio de Janeiro, 2015.

SILVA, F.; LEÃO, K.; ALMEIDA, F. Atlântico: A História de um Oceano. Rio de Janeiro: Civilização Brasileira, 2013.

SIPRI. Military Expenditure Database. 2014. Disponível em <http://goo.gl/tdwBZm>. Acesso em: 30 abr. 2015.

SPEKTOR, M. O Brasil e a Argentina entre a cordialidade e o projeto de integração: a política externa do governo de Ernesto Geisel (1974-1979). Revista Brasileira de Política Internacional, Brasília, v. 45, n. 01, p.117-145, 2002.

VIDIGAL, A. Conflito no Atlântico Sul. Rio de Janeiro: Escola de Guerra Naval, 1984.

VIEIRA, F. Modelo Travassiano: A Geopolítica que guia o Brasil na Democracia. Rio de Janeiro: Milênio, 2008.

WEIFFEN, B.; WEHNER, L.; NOLTE, D. Overlapping regional security institutions in South America: The case of OAS and UNASUR. International Area Studies Review, Londres, v. 14, n. 04, p. 370-389, 2013. 